\title{
Re-Envisioning the North: The Importance of Effective Cultural Planning for Economic Growth \& Sustainability in Northwestern Ontario Rural Communities
}

\author{
Suzanne Kukko, B.F.A
}

Since the fall of the forestry industry over a decade ago, Northwestern Ontario has struggled to find its footing in an ever changing, global economy. As the hub of NWO, Thunder Bay has kept their economic engine fired through the facilitation of research and development, and by aggressively promoting itself as a travel destination. But without an anchor industry, research facilities, and major infrastructure, how will northern rural communities continue to sustain themselves? In today's economic climate, diversification and sustainability must be achieved through attraction of creative talent. Peeling back the layers of the development happening within Nipigon, a small town $110 \mathrm{~km}$ east of Thunder Bay, we see that such a transformation is beginning to happen, although not by design. What is Nipigon already successfully doing to transform itself into a creative community? What deliberate actions should it take to achieve further success? Through the development and facilitation of a cohesive cultural planning strategy, Nipigon will be an evolutionary model for other northern rural communities experiencing similar economic challenges.

Key Words: cultural planning, creative community, sustainability, arts, culture, north

\section{Introduction}

This paper discusses the economic transition that Canada's rural regions are undergoing, as well as the challenges and opportunities Northwestern Ontario towns in particular experience in reinventing themselves as "creative communities". Especially in isolated towns where large, industrial resource-based economic drivers such as mills and mines were once the main employer but no longer exist, diversification of the local economy by attracting creative talent is vital for economic sustainability. Being a Creative Community means protecting your unique heritage properties, having a thriving downtown core, appealing to entrepreneurs starting new businesses, and generating new wealth. It means being a "Smart Community". It means respecting the environment. It means being innovative and progressive as a community. It means having "buzz" (Hume, 2009).

Through the case study of Nipigon, Ontario, this paper suggests that cultural planning is a vital piece in preparing rural communities for the ebb and flow of the modern economic climate.

\section{Nipigon, Ontario - Background}

The Township of Nipigon is located $110 \mathrm{~km}$ east of Thunder Bay, ON. Its population, approximately 1661 , is significantly lower than the peak of 5,000 in the 1950s and 60s when logging and forestry were the dominant industry and the mills were active. Many residents have been forced to leave the community to seek employment following the mill closures in Nipigon 
(2007) and the neighbouring town of Red Rock (2006); however, a number of families remain in the community while a family member 'works away' at mines elsewhere in Northern Ontario or Alberta (DPR Canada, 2014). In light of the mill closures and the downturn of the forestry industry, which has historically been the main source of employment and business opportunities in Nipigon and the surrounding area, the town has re-focussed its economic development efforts onto the tourism sector. A \$5 million downtown revitalization project was completed in 2009 that included a new municipal/library building and the construction of Paddle-To-The-Sea Park in the downtown core. In 2013, Nipigon release the Waterfront Development Master Plan. Phase 1 of the plan - which is a $\$ 2.8$ million project that includes hard infrastructure (water and sewer lines to the marina), a lookout tower, lagoon boardwalk, and an enhanced events park-is anticipated to be completed in 2017. $\$ 2.2$ million of the project is being funded by the provincial and federal governments. Additional tourism projects include a Trails Infrastructure Strategy and a Signage and Promotion Strategy to attract the 93,000 unique travellers that pass through the area during the peak tourism season. The Township will also use this strategy to draw visitors from the Thunder Bay area, the Northern United States, and beyond.

\section{Why Become a Creative Community?}

It is important for Nipigon's economy to build infrastructure that will attract tourists, however, it is imperative that town leaders recognize that cultural planning is also vital for growing the economy. As has been proven, having a vibrant, attractive community is one of the things that separate Canadian municipalities from many others around the world. That ranges from a good library system, to arts and cultural opportunities, to providing safe water. What a municipality does, in fact, makes a difference (Hume, 2009). Ours is a global economy. Nipigon is not just competing with Terrace Bay, Thunder Bay, or Toronto for talent, it is competing with Japan, India, the UK, and the USA, among others. Nipigon, like other small towns, is in a time of transition. Challenges for rural communities in Canada and abroad include declining and aging populations, problems with youth retention, limited economic and social opportunities for residents, depleting natural resources, loss of local services, and higher costs of living (Campbell $\&$ Duxbury, 2011). On the surface, the future might seem bleak for Canadian rural towns, however with a proactive attitude and proper cultural planning, towns like Nipigon can survive and thrive in the new global economy, despite small populations and geographical isolation.

\section{Becoming a Creative Community - The Importance of Cultural Planning}

\section{Community Buy-In}

Prior to beginning any type of plan or strategy, it is vital that the Economic Development Department rally support from both the town council and community members. After all, this strategy will need the citizens to work together towards a common goal. It will also require monetary and resource investment on behalf of the Township. The Economic Development Office could present the case for the importance of cultural planning to council and community 
by pointing to The External Advisory Committee on Cities and Communities (the Harcourt Commission). The 2006 report was created by the federal government to provide a snapshot of where Canadian cities will be within a 30 year span. The report listed economic prosperity, social equity, environmental sustainability, and cultural vitality as the four "pillars of sustainability" for communities. The commission also noted, "Creativity and innovation are together the overall elements to propel cities to success" (Hume, 2009, p. 2). Once the mayor and council is in full support, the department should hold a town hall style meeting outlining what cultural planning is, what it means to be a "creative community", why the Township of Nipigon should support a Cultural Planning Strategy, and the implementation of that strategy. The role of governance in this situation must be community driven to preserve a bottom-up, sustainable program of culture-led regeneration. Regional art officers and networks of support may be key to these efforts (Campbell \& Duxbury 2011).

Once the Economic Development Office has buy-in from council and community, the EDO will research funding options, and proceed with applying to government programs to pay for a portion of the cost to complete the Cultural Planning Strategy. The strategy will organize the efforts of the township by taking inventory of what has already been achieved in relation to the four pillars of sustainability as described above.

\section{The Time is Right}

The question of "right timing" is also an important aspect of discussions of governance as often there needs to be an accurate reading of a community's resources, capacity and assets before a plan of revitalization can be fully acted upon (Campbell \& Duxbury, 2011). The time is indeed "right" for Nipigon to embark on a full transition into a Creative Community for two main reasons. First, the township has, and not by design, already taken a number of steps in this direction. For example, what is currently being done in pursuit of environmental sustainability. The town operates a recycling depot, which is funded $100 \%$ by the municipality. They are in the process of beginning a storm water project, and tire and e-waste can be recycled at its landfill site. Volunteer community members formed a committee in 2015 out of a concern for climate change's impact on lifestyle, economy, and sustainability for future generations. The Nipigon Eco-Team is an independent, arms-length committee that makes recommendations to mayor and council, organizes events and initiatives, and promotes environmental responsibility to the citizens of Nipigon and the surrounding communities of Lake Helen (Red Rock Indian Band) and the Township of Red Rock.

In addition to being environmentally proactive, over the past five years Nipigon has been advancing in the pillar of social equity. A number of non-profit organizations and groups work together towards achieving food security through the implementation of programs such as the Good Food Box and Meals on Wheels. As well, volunteer church organizations operate a Food Bank and Thrift Store .The Best Start Centre offers daily, free, drop-in programs for parents and caregivers of children under 6 years of age. The centre offers parenting, health and nutrition 
programs, as well as a licensed daycare that has supplemented spaces reserved for low income families. There are also a number of housing options including apartments and houses offering rent geared to income. A senior housing project is being undertaken in 2017 to provide affordable one- and two- bedroom rental apartments for community members 55 and older.

In regards to economic prosperity, the town is currently in an upswing due to two major government-funded projects underway in close proximity to the municipality. In 2009, construction commenced on the $110 \mathrm{~km}$ four-laning of Trans-Canada Highway 11/17 between Thunder Bay and Nipigon. By 2017, the $\$ 500$ million project is proposed to be approximately $50 \%$ completed. In 2014, construction began on the new \$106 million plus Nipigon River Bridge which is located less than a kilometre east of Nipigon. The bridge consists of two cable-stayed sections, one of which was completed in 2016.

There were approximately two years between the closing of the regional mills, and the commencement of these million dollar government projects. During those years, there was a mass exodus of skilled workers and their families, who needed to move where they could find opportunities for employment. However, since these projects began, Nipigon has experienced an economic boom. Families from outside the province, and outside of Canada have migrated to Nipigon. For seven months of the year, motels often have no vacancy as they provide accommodation for construction workers, inspectors, engineers, etc. Rental accommodations are at zero vacancy and are charged at a premium. The restaurants, grocery store, pharmacy, shops, and tradesmen are experiencing far above average volumes of business. As this boom has been going strong for approximately 3-4 years, the community is becoming comfortable in this state. When the bubble begins to deflate upon completion of the Nipigon River Bridge in 2018, the Township of Nipigon needs to have strategies in place to ensure a smoother transition for local businesses and organizations. Following the fall of the forestry sector, the focus of the economic development office also shifted to the tourism sector, which was viewed as being more sustainable than the forestry and wood processing. Although tourism has the potential to grow Nipigon's economy, peak season is approximately June through September. As such, it important for the Township's economic success that it diversify its economy beyond the major government sponsored projects described above. In preparation for this, the Economic Development Department has completed a Nipigon Asset Inventory, which is a digital database of residential and non-residential assets/properties, both serviced and un-serviced. This database will be made available to new residents, potential investors, and site selectors on demand. An Economic Development Strategic Plan is anticipated to be completed by 2018.

The fourth pillar - cultural vitality - is the main area where Nipigon is in need of more vision. There are a number of challenges the township faces, but also many opportunities that can be taken advantage of in furthering its cultural planning efforts. 


\section{Mill Town to Creative Community?}

\section{The Challenge of Convincing an Aging Demographic}

Community and Council buy-in may be an issue. $50 \%$ of Nipigon's population is 55 and over. Many were born and raised in the region, which was built on the "blue collar" logging/forestry/paper industries. (DPR Canada, 2014) Generally speaking, this senior population may have their heels firmly dug in when it comes to discussions about developing arts and culture in Nipigon for economic growth and sustainability. In the past, economic developers chased "smoke stacks", or large industrial companies to have them set up shop in their communities. As the global economy developed and manufacturing moved to where labour was cheaper, developed countries like Canada lost many of their industrial jobs, and investment from large manufacturing corporations largely dried up. Although this is a reality, it may be difficult for the senior population, and council (majority who are 55 plus) to accept that a large scale industrial plant will most likely never again be based in the Township of Nipigon.

In order to overcome this challenge and obtain support, the Economic Development Office must provide clear evidence to support the idea of Cultural Planning. The EDO should start by gaining support for a small, modestly budgeted project such as the Superior North Youth Arts and Culture Strategy. The Township of Nipigon has obtained a seed grant from the Ontario Trillium Foundation to complete this strategy. As public funding is now available, the plan will cost the town no more than $\$ 3,000$ to execute. Such expenditures have received minimal public pushback.

The strategy is expected to be completed in August of 2017. Upon its completion, the Economic Development Office will use it as evidence that becoming a Creative Community is vital to the economic sustainability of the town. Once phases are implemented, the success of the cultural plan could be measured through quantifiable indicators over a set period of time. Nipigon's goals could begin with a change in demographics, for example. Perhaps beginning with the objective of increasing its population, and therefore tax base, by $5 \%$ (or 83 individuals) by 2022, with the goal of welcoming five new business start-ups (one per year) and retaining or growing the current businesses during the same period. Other indicators that can be measured for increases over the same period include housing starts, attendance patterns at historical sites and the museum, library usage, and website visits. It is important that an effective communications strategy be devised as part of the Superior North Youth Arts and Culture Strategy to ensure support from the community in the early stages of the planning process and throughout the implementation of the plan. It is also important to share successes, no matter how small, to continue to sustain support throughout the process.

\section{The Challenge of Youth Engagement}

Numerous studies include recommendations for governance of cultural development in rural communities, with six dominant and reoccurring categories (Campbell \& Duxbury, 2011). One 
of these categories is the engagement of youth, with a focus on capacity and retention through employment, recreational, and educational initiatives. The staff and council, through their commitment to the Economic Development Office's most recent initiatives, have demonstrated their recognition that youth engagement is vital to the future sustainability of our community.

Through the Superior North Youth Arts and Culture Strategy mentioned earlier, regional youth and the general populations will be consulted by Laridae Communications to assess demand for creative arts programs, specifically for youth aged 12-25, in the communities of Lake Helen, Nipigon, Red Rock and Dorion. In addition, potential partners and stakeholders will also be consulted, and gaps and opportunities will be identified in regards to infrastructure. The strategy will also identify program mentors, and outline potential opportunities for funding of arts and/or culture infrastructure and programming. The steering committee consists of artists, leaders, and youth from all four communities, as well as a representative from Parks Canada. Upon completion of the project, the strategy will be shared by all four communities with the vision of working together to leverage funding and human resources to establish a regional, vibrant arts and culture scene that encourages engagement of youth with and without barriers to become leaders, volunteers and entrepreneurs in the communities.

Another youth engagement project the Township of Nipigon's Economic Development Office has created and is currently implementing is an entrepreneurship program called "adVENTURE North". This initiative, funded in part by the Ontario 150 Partnership Program, will bring existing programs to the community through a non-profit organization called Head Start in Business, and utilize local resources to inspire and foster entrepreneurship in local youth aged 10-25. Coordinated through a partnership between the Township of Nipigon and Red Rock Indian Band, the project will expose youth to the possibilities of self-employment, "planting the seed" of entrepreneurship through in-school programming. It will further develop the entrepreneurial ideas of those inspired by in-school programs, through an age appropriate, intensive, one day workshop. Finally, it will help make ideas a reality through a Dragon's Den style public "Bear Cave" where young entrepreneurs will pitch their ideas to a panel of mentors. Mentors will provide feedback on concepts, and start-up seed money will be available through the Ontario 150 Partnership Program funding. Each young entrepreneur will be matched with a local mentor.

adVENTURE North will encourage youth to think outside the box, discovering their potential to generate their own summer employment and possibly, consider being an entrepreneur as a long term career choice. For those who may not be fully committed to being their own boss, the project will foster in youth the values, attitudes, qualities and skills needed to be successful in today's economy. High energy games and activities will teach financial awareness, confidence, teamwork and communication skills. This project will spark the entrepreneurial spirit of youth who might not have thought of themselves as a business owner, and will inspire those who have business ideas to take the leap into entrepreneurship. Youth from Lake Helen Reserve to Dorion will be encouraged to participate. Both the youth and local communities as a whole will benefit, 
as financial literacy and employability skills are essential concepts that are rarely taught at home and are not covered in school curriculum. Bringing such skills to local youth will nurture individual success, and help the north shore communities realize their collective vision of a sustainable local economy.

Although these two youth focussed projects are a vital starting point, it is important that the Township of Nipigon continue to work with its neighbouring communities to actively engage youth in all of its initiatives - including civic pride, volunteerism, economic development, and cultural planning - as youth retention is an important piece of building and maintaining a successful, sustainable community.

\section{Conclusion - A Collective Vision for Success}

Arts, culture, and heritage are increasingly viewed not only as amenities to improve the quality of life, but as a foundation upon which the future of rural/small communities rests (Campbell \& Duxbury, 2011). Nipigon's evolution from an industrial mill town to a culturally relevant, creative community that welcomes new ideas, innovation, and entrepreneurship, is an ongoing process that must be continuously focussed on if it is to progress. Considering the projects the Township has completed over the past decade, and the initiatives it is currently undertaking, this rural Northwestern Ontario town is already taking positive steps towards becoming a creative community.

As has been evident in this paper, one of the major steps in moving toward this objective is establishing and continuing to sustain successful, relevant partnerships. Individually, an artist or small arts organization may have very little capacity to generate cultural, economic, social or environmental impact on a scale likely to attract investment. However, collectively, a group of creative people and organizations banded together can have an impact much bigger than the sum of their individual parts (Hume, 2009).

Nipigon currently enjoys such a relationship with Parks Canada, whose Lake Superior National Marine Conservation Area (LSNMCA) headquarters are located in Nipigon. The Parks Canada brand is trusted, and well recognized across Canada and worldwide. This agency of the Government of Canada is known for providing world class, quality experiences. In July of 2015, Nipigon partnered with Parks Canada to host the Nipigon River Brook Trout Festival, to celebrate the $100^{\text {th }}$ anniversary of the world record brook trout caught on the Nipigon River. Parks Canada offered guided boat tours to view the native pictographs on the rock cliffs along the east shoreline of the Nipigon River. In August of 2016, the Township partnered with the LSNMCA to host artESCAPE, an open air art gallery that showcases local artists who find inspiration in the coasts and waters of Lake Superior. The goal of the event was to promote local artists, and market the LSNMCA as the inspiration for a number of Group of Seven paintings. This is an example of a relationship that the Township must actively build on if it is to continue its quest to be recognized as a cultural community. 
Another important partner is the Red Rock Indian Band, who the Township is working with to deliver the adVENTURE North Project. Nipigon is also looking to local artists, teachers, and cultural leaders from all four neighbouring communities to participate in the process of completing the Superior North Youth Arts and Culture Strategy. Arts and cultural activities are not the answer to all the issues of rural communities - there are no simple solutions to addressing the complex situation of sustaining rural communities into the future - but culture can play important roles in the process of community adaptation, development and, sometimes, reinvention. (Campbell \& Duxbury, 2011) By creating a Cultural Plan that would identify where the gaps are, set out a plan to mitigate any risk, set goals and project outcomes, and provide a road map for achieving these, the Township of Nipigon will keep focussed and on-track to successfully realize its ultimate goal of becoming a true creative community, thus, trailblazing a path for other northern communities in transition to follow in its footsteps.

\section{Author biography}

Born and raised in Thunder Bay, ON, Suzanne Kukko received her Bachelor of Fine Arts from York University (Toronto) in 1998. She lived in Ottawa for seven years, where she owned and operated a successful media production company. Her clientele included Parks Canada, City of Ottawa, and Correctional Service of Canada, among others. Ms. Kukko currently resides in Nipigon with her husband and two children, where she has been the Economic Development Officer since 2014.

\section{References}

Campbell, H., Duxbury, N., (2011). "Developing and Revitalizing Rural Communities through Arts and Culture". Small Cities Imprint, Volume 3.

DPRA Canada. (2014). “Community Profile, Township of Nipigon, Ontario”. Toronto.

Hume, G. (2009). Cultural Planning for Creative Communities. Union: Municipal World. 